\title{
Examining the literacy histories of doctoral students in an educational studies program through surveys and interviews: A mixed methods study
}

\begin{abstract}
Melissa Adams-Budde ${ }^{1}$, Christy Howard ${ }^{1}$, Grant Jolliff ${ }^{1}$, Joy Myers ${ }^{1}$
Abstract: The purpose of this mixed methods sequential explanatory study was to explain the relationship between literacy experiences over time and the literacy identities of the doctoral students in a teacher education and higher education program. The quantitative phase, surveying 36 participants, revealed a positive correlation between participant's present and past literacy experiences, suggesting that past literacy experiences impacted their present perception of themselves as successful doctoral students. In the qualitative follow up multiple case study analysis, four major themes emerged from the interviews and participants' visual representations: (1) past literacy experiences; (2) present literacy experiences; (3) support systems; and (4) social experiences. The findings suggest that early feelings of success in literacy contribute to strong literacy identities in higher education programs. Implications for the faculty of higher education will be discussed.
\end{abstract}

Keywords: literacy identity, doctoral students, literacy experiences, teacher education, higher education

\section{Introduction}

Within the field of education, doctoral student attrition rates are estimated at $50 \%$ (Ivankova \& Stick, 2007). High attrition of doctoral students is costly to the learning institution, to the faculty, and to students (Gardner, 2009a). Scholars have looked at various factors to determine reasons for persistence in doctoral programs from student characteristics, academic records, and advising and support structures (Gardner, 2009b). Researchers have found that strong literacy identities, as well as support systems, are connected to students' ability to succeed in master's and doctoral programs (Mullen, 2001; Onwuegbuzie, 1997).

Graduate programs require extensive reading and writing for success and persistence. Many graduate students often face challenges adjusting to the academic rigor of advanced coursework. Hall and Burns (2009) discussed the identity transformation of students coming into doctoral programs. Often students enter a program with perceived literacy capital that holds little value in doctoral studies. These students must negotiate their identities in order to become valued readers and writers of research. Wao et al. (2009) found that perceived time restrictions and reading vocabulary were factors in a doctoral student's ability to consume and process research. Mullen (2001) discussed how doctoral students often struggle with their self-perception as writers and researchers. Knowledge and understanding of factors contributing to doctoral students' past, present and future literacy identities may help academic institutions better meet

\footnotetext{
${ }^{1}$ Department of Teacher Education and Higher Education, University of North Carolina Greensboro, 1300 Spring Garden St., Greensboro, NC 27402, meadamsb@uncg.edu
} 
the graduate students' needs, improve the quality of their academic experiences, and reduce graduate program attrition rates.

The purpose of this explanatory mixed methods study was to examine how doctoral students' literacy identities shape their experiences in the program. Our assumption prior to beginning the study was that experiences in a doctoral program are influenced by students' literacy identities. We believe that past experiences with reading and writing shape how doctoral students see themselves, thus impacting their literacy identity. That identity in turn shapes their experiences and success in the program. Specifically, this study explored how past and present literacy experiences contributed to participant's identities as readers and writers within a teacher education and higher education (TEHE) program.

\section{Literature Review}

This study is grounded in a sociocultural perspective. Language and learning are socially constructed and situated experiences, embedded in the cultural context in which we live (Vygotsky, 1978). For the purposes of this study we draw from the work of Gee (2006) and define literacy identity as a co-constructed and socially situated sense of self which shapes the individual's perceptions of their world over time. This definition implies one's literacy history past experiences with literacy - as critical in shaping one's literacy identity. Moreover, Holland, Lachicotte, Skinner, \& Cain, (1998) assert that identity is historically dependent, socially enacted and culturally constructed understandings or objectifications of the self or a group. These understandings are produced from the interaction of individuals' personal worlds with collective spaces and social relationships. They call these collective spaces figured worlds.

Institutions are active in the process of individual identity construction (Holland et al., 1998). The home, the community and the school are distinct but overlapping figured worlds in which people develop reading and writing identities. These identities develop over time, are influenced by numerous social and cultural experiences, and expressed according to social and cultural norms (Skerrett, 2012). Identity is socially constructed and is often tied to group membership (Moje \& Luke, 2009). Individual's identities are shaped and reshaped within the context of their figured worlds. Because of this, identity is neither static nor singular (Lave \& Wenger, 1991).

An individual's sense of self, or identity, can be understood through stories (McAdams, 1993) and visual representations (Bustle, 2004). Drake, Spillane, \& Hufferd-Ackles (2001) used literacy stories as representations of participants' literacy identities. The stories shared were set both at school and home and served as the lens through which participants understood themselves personally and professionally (Drake et al., 2001). Williams (2003) has looked at literacy narratives that students created highlighting their prior literacy experiences and their general feelings towards reading and writing. Hayik (2012) asked students to create visual representations in the form of collages to represent identities. Narratives and visual representations can be used to communicate the identities that students construct.

Many studies have been done to understand student literacy identities (Guthrie \& Alvermann, 1999; McCarthey, 1998, 2001; Skerrett, 2012; Williams, 2003). The findings of these studies reveal that students' literacy identities are fluid, shaped by contexts, tasks, and family and cultural expectations. There are additional studies that examine doctoral student success in graduate programs. Ivankova and Stick (2007) found five external and internal factors to be predictors of students' success and persistence - environment, program, student support, 
faculty, and self motivation. Gardner (2009b) discusses the difficulties defining success at the doctoral level, and identifies the various indicators that have been used to demonstrate success, such as retention, academic achievement, graduation, and professional socialization. Drawing on Gardner's work, for the purpose of this study of current doctoral students, we defined academic success using the following indicators: retention, academic achievement, and professional socialization. Despite research in the fields of literacy identity and doctoral education, a gap in the literature remains linking students' literacy identity to their experiences in a doctoral program.

\section{Research Questions}

Based on the review of the literature, we posed the following research questions to guide our study, which examined the literacy histories of doctoral students in an educational studies program. The quantitative question that guided phase one was: How do doctoral students rate their past literacy experiences and the impact of these experiences on their current literacy identities? The qualitative question that guided phase two was: What are the perceived literacy identities of doctoral students in a TEHE program? The question that guided the mixed methods section was: How do past literacy experiences impact the literacy identities of doctoral students in a TEHE program?

\section{Method}

\section{Study Design}

This study used a mixed methods sequential explanatory design with two distinct phases (Creswell \& Plano Clark, 2011). The rationale for using this design was to first collect quantitative data that would inform the selection of interview participants in order to be able to explain and expand on the results from the quantitative data. The mixed methods approach also provided an opportunity to triangulate data (Bryman, 2006; Greene, Caracellli, \& Graham, 1989; Johnson, Onwuegbuzie, \& Turner, 2007), and was implemented in order to gather numerical data and include rich, thick descriptions of participants' literacy experience in their own voices. Although typically priority is given to the quantitative data in a mixed methods sequential explanatory design (Creswell, \& Plano Clark, 2011), in this study the priority was placed on the qualitative data. Ivankova, Creswell, and Stick (2006) asserted that priority can be determined based on study goals and the particular design of each phase. In this study, our goals were to understand the "hows and whys" (Yin, 2009) of doctoral students' identities and experiences and amplify their voices through interviews and visual representations.

\section{Participants}

At the time of this study, the participants were enrolled in the TEHE Ph.D. program offered by a university in the Southeast region of the United States. All 74 current doctoral students were invited by the research team to participate via email. The email contained details of the study, a consent form including potential risks and benefits, contact information, and a link to the survey. Of the 36 consenting participants, $11 \%$ were in year one, $36 \%$ in year two, $22 \%$ in year three, $19 \%$ in year four, $8 \%$ in year five, and 3\% in year six. Forty two percent of these 
students had a concentration in higher education, and 58\% in teacher education. There were 24 females and 12 males. Ages ranged from 25 to 63 with the mean age of 40 .

\section{Instruments and Procedures}

The survey instrument used in phase one was developed by the researchers guided by the existing literature on literacy identity (Gee, 2006; McCarthy, 2001; Moje \& Luke, 2009). To increase the validity of the survey, it was shared with three expert reviewers in the fields of literacy and/or identity prior to distribution. Based on feedback from the reviewers, the survey was revised to more precisely address the research questions. Thirty-six participants completed the survey, yielding a 48.6\% response rate. The survey instrument asked 10 questions which were answered on a five-point Likert scale ranging from Strongly Disagree (1) to Strongly Agree (5). These questions elicited information regarding participants' past and present literacy perceptions and attitudes (See Table I). The reliability of the survey was .84 according to Cronbach's alpha.

Descriptive statistics and an independent t-test were used to analyze the survey data. The descriptive statistics were used to measure mean scores on the ten survey responses. An independent t-test was utilized to determine if there was a significant difference between participants' perceived past literacy identity. Participants were divided into two groups based on their responses to question five, "Growing up, I was a successful reader and writer". Those who reported 1 or 2 on the Likert scale retrospectively identified themselves as less successful readers and writers (low literacy identity group), while those who reported 3 or above on the Likert scale self-identified as more successful readers and writers (high literacy identity group). In order to examine participants' past and present literacy experiences and compare how these experiences differ among participants' with higher verses lower literacy identity as determined by their responses to question five, an independent t-test was utilized.

Phase two used an explanatory multiple case study design, with each participant representing a separate case (Yin, 2009). This phase sought to explain the "hows and whys" of doctoral students' identities and experiences. In-depth data collection was conducted involving multiple sources of information reporting case descriptions and case-based themes (Creswell, 2003). Two cases from the larger study will be shared in this article. In order to provide a broader lens to examine literacy identity and contrasting perspectives, one participant was chosen from each concentration - higher education and teacher education. In addition, participant one was selected based on high survey data scores, whereas participant two demonstrated below average scores on the survey.

The data were collected from multiple sources (Yin, 2009) in order to provide an accurate understanding of doctoral student's perceived identities and how past literacy experiences impacted these identities. The data included: (1) semi-structured interview questions (Schensul, Schensul, \& LeCompte, 1999), (2) visual representations. The interview protocol grounded in literacy identity research (Gee, 2006; McCarthy, 2001; Moje \& Luke, 2009) and reviewed by three experts in the field - was used to obtain the participants' literacy stories. Members of the research team independently conducted interviews that ranged thirty minutes to an hour long with each participant. The interview asked eight questions. Example questions included: "How did your school literacy practices impact how you read and write today?" "How does literacy (reading, writing, speaking, listening) impact your daily life?" "How have your literacy histories shaped your experiences in the doctoral program?" Participant stories were 
constructed as they shared about and reflected upon their past experiences with reading and writing and how these experiences shaped their current literacy identity in the TEHE doctoral program.

Participants were asked to create a visual representation prior to the interview that illustrated their literacy identity. The term visual representation is used purposefully to include a wide range of visual meaning and making devises as well as symbols (Bustle, 2004). This activity was created as a tool (Shephard, 1993) for both the process for and a representation of doctoral students' understanding of their literacy identities. The prompt for this activity was intentionally open ended to allow participants to express themselves in whatever way they saw most appropriate. The visual representation allowed researchers another opportunity to view students' perceptions of their literacy identities without the pressure of providing standard responses to questions posed in the survey and interview to illustrate their literacy identities. A researcher met with each participant and asked them to explain their visual representation.

Each interview was audio recorded and transcribed by researchers. One interview was coded individually by all four researchers. Researchers collaborated to compare and discuss the results of independent coding. From this process nine initial descriptive themes (Miles \& Huberman, 1994) emerged: past home, past school, past professional, present school, present home, present professional, social/support experiences, beliefs, and future professional. Using the initial codes each researcher reexamined the originally coded interview to develop and revise interpretations of the data using constant comparative analysis (Strauss \& Corbin, 1998). In this process, researchers made comparisons of initial data analysis to reduce, display, and draw conclusions from data (Miles \& Huberman, 1994). Following this analysis and discussion among researchers, the nine themes were collapsed into four: past literacy experiences, present literacy experiences, support systems and social experiences. Each researcher independently reviewed and coded the remaining transcribed interviews using the four themes. Coding agreement among researchers exceeded ninety percent and discrepancies were settled through discussion. Member checking (Lincoln \& Guba, 1985) was used to confirm and verify the findings from each interview and the interpretations of the visual representations. Case study write-ups were shared with participants and feedback was solicited. Once the themes were established, each visual representation along with notes from the participants' explanation was analyzed for evidence of the themes thus providing triangulation.

\section{Results}

\section{Quantitative Findings}

The findings from this phase answered the quantitative research question, regarding how students rated their past literacy experiences and their current literacy identities. The mean scores from the survey indicate that on average, people rated their past literacy experiences highly. In addition, they also highly rated the impact of their past experiences on their current identities (See Table 1).

The Inter-Item Correlation Matrix indicated a significant positive correlation $(\mathrm{p}<.05)$ between two questions; question five "Growing up, I was a successful reader and writer," and question nine "I am a successful doctoral student in part because of my previous experiences with literacy." In contrast, although not significant, a negative correlation was found between question five "Growing up, I was a successful reader and writer," and question eight "My 
previous writing experiences have been useful to my work as a doctoral student." Although these results suggest that participants believed previous literacy experiences prepared them for the doctoral program, they did not feel as prepared for academic writing.

Table 1

Survey Questions with Means

\begin{tabular}{|c|c|c|c|}
\hline Question & $\underline{\mathrm{N}}$ & Mean & $\frac{\text { Standard }}{\text { Deviation }}$ \\
\hline Q1. I have always enjoyed reading. & 36 & 4.23 & 1.17 \\
\hline Q2. I have always enjoyed writing. & 36 & 3.57 & 1.33 \\
\hline $\begin{array}{l}\text { Q3. Growing up, reading and writing } \\
\text { were encouraged in my home. }\end{array}$ & 36 & 4.00 & 1.11 \\
\hline
\end{tabular}

Q4. Growing up, reading and writing $\quad 36 \quad 3.42 \quad 1.42$ were modeled in my home.

Q5. Growing up, I was a successful reader and writer.

$\begin{array}{lll}36 & 4.31 \quad .99\end{array}$

Q6. My previous literacy experiences

$\begin{array}{lll}35 & 3.31 \quad 1.32\end{array}$ impacted my decision to pursue a graduate degree in my field.

Q7. My previous reading experiences

$\begin{array}{lll}36 & 4.17 \quad 1.07\end{array}$ have been useful to my work as a doctoral student.

Q8. My previous writing experiences

$\begin{array}{lll}36 & 4.22 & 1.01\end{array}$ have been useful to my work as a doctoral student.

Q9. I am a successful doctoral student in

$\begin{array}{lll}36 & 4.14 \quad .94\end{array}$ part because of my previous experiences with literacy.

Q10. I believe that my previous literary $\begin{array}{lll}36 & 4.31 \quad .83\end{array}$ experiences will positively impact my future career. 
An independent $t$-test was run to compare the means of question five with the rest of the questions. To prepare the data for this $t$-test, the sample scores were collapsed into two groups and compared across groups. Group one represented the lower half of the Likert scale, and Group two the upper half. The $t$-test found no significant differences between Groups one and two when comparing past literacy identity (question five) and the other variables (questions 1, 2, $3,4,6,7,8,9)$, showing that previous literacy identity did not necessarily determine present experiences with literacy in the doctoral program $(p>.05)$ Means for Group one were higher than those for Group two in questions four, eight, and nine, indicating that for these questions the survey respondents saw their previous literacy experiences yielding slightly smaller influences on their current literacy identities (See Table 2). The highest margin of difference was for question eight, "My previous writing experiences have been useful to my work as a doctoral student," with a mean of 4.71 (SD .76) for Group one, and a mean of 4.13 (SD 1.0) for Group two. Group one, who self identified as less successful in their previous reading and writing experiences, actually reported that these experiences were more impactful on their work as a doctoral student than participants from Group two who self identified as more successful in their previous reading and writing experiences. A possible explanation for this finding results from the identity transformation that doctoral students undergo throughout their program, which may be greater for those students that enter with high literacy capital and feel as if their previous success is not valued.

\section{Qualitative Results}

The findings from this phase illustrated the perceived literacy identities of doctoral students. The results of this phase yielded four themes representing these perceptions and the factors that shaped them. The four themes were past literacy experiences, present literacy experiences, social experiences, and support systems. While using these themes to analyze and discuss the findings, the researchers recognized that these themes were not necessarily discreet. The following are descriptions of the themes and how they were used in the study. Past literacy experiences were defined as occurring prior to entering the doctoral program. Present literacy experiences referred to experiences during the period of time in which the participant is enrolled in the doctoral program. Social experiences involved others in a meaningful way. Support systems were individuals or groups who supported the participant's literacy experiences in the doctoral program. The following two cases highlight the four themes. Pseudonyms have been used to protect the identity of participants.

Catherine, the first case study, was a third-year full-time doctoral student in the department of TEHE. Her focus area was teacher education, with her interests concentrated on middle grades and literacy. When she finished the program she hoped to have a tenured track position as a professor. The three words Catherine used to describe herself as a reader were curious, a detective, and dedicated. In describing herself as a writer, Catherine chose the words: versatile, communicative, and a way to help her think. Catherine created a magazine cover as a visual representation of her literacy identity (see Figure 1). 
Table 2

\section{Group Statistics}

\begin{tabular}{|c|c|c|c|c|c|}
\hline Question & $\underline{\mathrm{LI}}$ & $\mathrm{N}$ & Mean & $\underline{\mathrm{SD}}$ & $\underline{\mathrm{SE}}$ \\
\hline \multirow[t]{2}{*}{ I have always enjoyed reading } & 1 & 7 & 4.14 & 1.21 & .46 \\
\hline & 2 & 9 & 4.28 & 1.16 & .22 \\
\hline \multirow[t]{2}{*}{ I have always enjoyed writing } & 1 & 7 & 3.71 & 1.25 & .47 \\
\hline & 2 & 29 & 3.55 & 1.35 & .25 \\
\hline Growing up, reading and & 1 & 7 & 4.14 & 1.10 & .40 \\
\hline $\begin{array}{l}\text { writing were encouraged in } \\
\text { my home. }\end{array}$ & 2 & 29 & 4.00 & 1.13 & .21 \\
\hline Growing up, reading and & 1 & 7 & 3.14 & 1.35 & .51 \\
\hline $\begin{array}{l}\text { writing were modeled in my } \\
\text { home. }\end{array}$ & 2 & 29 & 3.52 & 1.43 & .27 \\
\hline My previous literacy & 1 & 6 & 2.50 & 1.38 & .56 \\
\hline $\begin{array}{l}\text { experiences impacted my } \\
\text { decision to pursue a graduate } \\
\text { degree in my field. }\end{array}$ & 2 & 29 & 3.48 & 1.27 & .24 \\
\hline My previous reading & 1 & 7 & 3.71 & 1.60 & .61 \\
\hline $\begin{array}{l}\text { experiences have been useful } \\
\text { to my work as a doctoral } \\
\text { student. }\end{array}$ & 2 & 29 & 4.31 & .89 & .17 \\
\hline My previous writing & 1 & 7 & 4.71 & .76 & .29 \\
\hline $\begin{array}{l}\text { experiences have been useful } \\
\text { to my work as a doctoral } \\
\text { student. }\end{array}$ & 2 & 29 & 4.13 & 1.03 & .19 \\
\hline I am a successful doctoral & 1 & 7 & 4.30 & .95 & .36 \\
\hline $\begin{array}{l}\text { student in part because of my } \\
\text { previous experiences with } \\
\text { literacy. }\end{array}$ & 2 & 29 & 4.13 & .95 & .18 \\
\hline I believe that my literacy & 1 & 7 & 4.14 & 1.07 & .40 \\
\hline $\begin{array}{l}\text { previous literacy experiences } \\
\text { will positively impact my } \\
\text { future career. }\end{array}$ & 2 & 29 & 4.34 & .78 & .14 \\
\hline
\end{tabular}




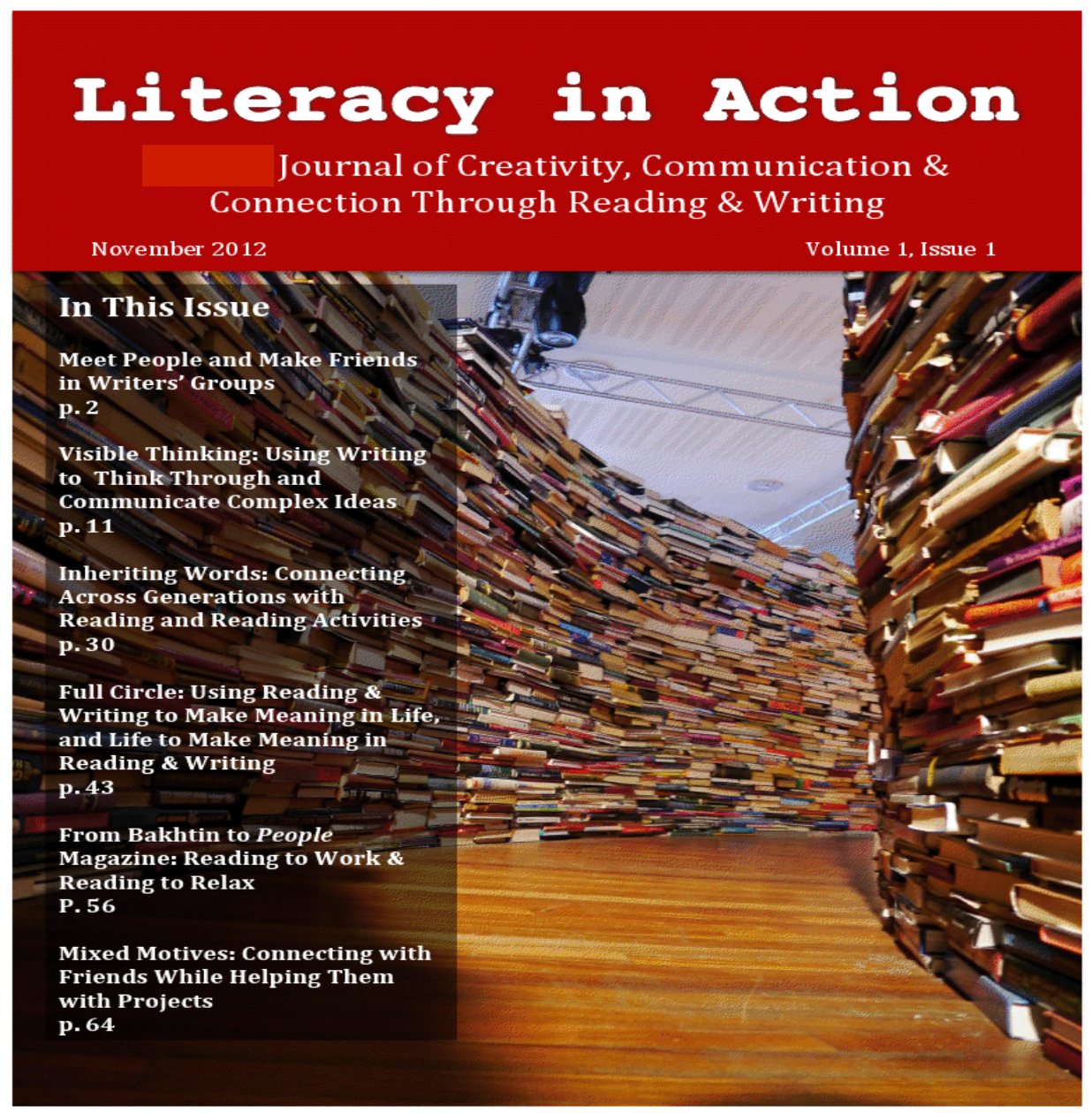

Figure 1. Catherine's visual representation.

Literacy played a large role in Catherine's life growing up, both at home and at school. She spoke about how her father loved books and was always reading. Catherine described visiting the library with her father as a child as an important home literacy experience by saying, "So I read, I think I read everything they had at the Chapel Hill library. So that really shaped my experience. You know it connected me to my dad. It gave me something that I could do that was free and I was good at." Catherine actively sought out reading and writing experiences that put her in the social circles she wanted to be a part of. She told about joining the yearbook staff in high school, which involved writing feature articles and required a writing sample to become a member. In college, Catherine was involved in a creative writing club. Also during college, Catherine worked at a bookstore. She and a co-worker started a reading series for writers to share original work with an audience.

Much of Catherine's present literacy experiences centered on her work in the doctoral program. Reflecting on her transition into the program, Catherine recalled feeling frustrated stating, "I did take it personally that the kind of literacy experiences I had or the kinds of writing I had done was not only not valued, but actively devalued." Catherine explained feedback she had received on her first paper completed in the program by stating, "I got a lot of critique that I needed to make sure all of my claims were warranted with evidence from published, academic, 
peer-reviewed, scholarly research." She explained that it took her time to build up literacy in the field and that she has had to "compartmentalize the parts of my literacy identity more since I have started this program."

Catherine explained two critical support systems that have helped her experience in the program. The first was her peers and in particular a writing/dissertation group that she was a member of and had organized. She noted, "I know it is going to be very useful to me to give me feedback, that is just to support me, to help me, that is not to evaluate me." The second support Catherine discussed was her advisor. Catherine described this relationship by stating, "I feel like she has really pushed me, but also really encouraged me in something that at first could have been very overwhelming to me."

Throughout the interview, Catherine continually highlighted the social nature of her literacy experiences. She explained, "I like to write to communicate with people, I don't necessarily like to craft something that no one else is ever going to see. Like even when I did a lot of creative writing, I was always in sort of a writer's workshop setting, so I was motivated by the deadline, knowing I had class coming up or knowing that I was going to be sharing it with my peers and I wanted it to be something they would like and I wanted it to be good." Many of the article titles on Catherine's visual representation also highlighted the social nature of Catherine's literacy experiences. From her early experiences of visiting the library with her father and writing letters with her camp pen pal, to her later experiences with the creative writing club and bookstore readings, Catherine sought out opportunities to co-construct her literacy knowledge and identity in a social context. This case illustrated the three indicators of academic success as previously discussed: 1) Retention: Catherine is still enrolled in the doctoral program; 2) Academic Achievement: Her discussion of taking critiques and using them to build her literacy in the field. In addition, Catherine has successfully completed her coursework, exam requirements and is currently working on her dissertation; 3) Professional socialization: Organization and participation in the writing group and critical conversations with her advisor.

Tabitha, the second case study, was a third year doctoral student in the department of TEHE. Her focus area was higher education and when she finished the program she hoped to be an administrator at a four-year institution in academic support systems. Tabitha scored in the below average range of survey responses. When asked to pick three adjectives to describe herself as a reader, Tabitha picked proficient, slow and inquisitive. As for adjectives to describe herself as a writer, she chose slow, effective and frustrated. Tabitha created her visual representation (see Figure 2) on a PowerPoint slide with eight different images of books.

While explaining her past literacy experiences, Tabitha took a walk back in time to remember how she first learned to read with help from her grandmother. She also vividly remembered being able to read before entering kindergarten and she shared that she experienced feeling like the "other" due to her advanced reading ability throughout her K-12 school experience. Her parents did not read for pleasure while she was growing up, but they provided access to reading materials. Tabitha described a shift in her attitude toward reading when she entered middle school where reading was required. She explained, "I saw reading as a barrier sometimes like when you get assigned reading like a punishment - a hoop to jump through so that definitely impacted my approach to reading and writing." This continued into high school and she no longer read for pleasure. However, in college, reading helped her deal with issues of racism and identity struggles around her culture. She remembered, "When I went to college that was time for me to explore through reading and I was introduced to a lot of philosophers and 
writers that wrote about things that I had been feeling. I learned how to articulate my thoughts through their texts."

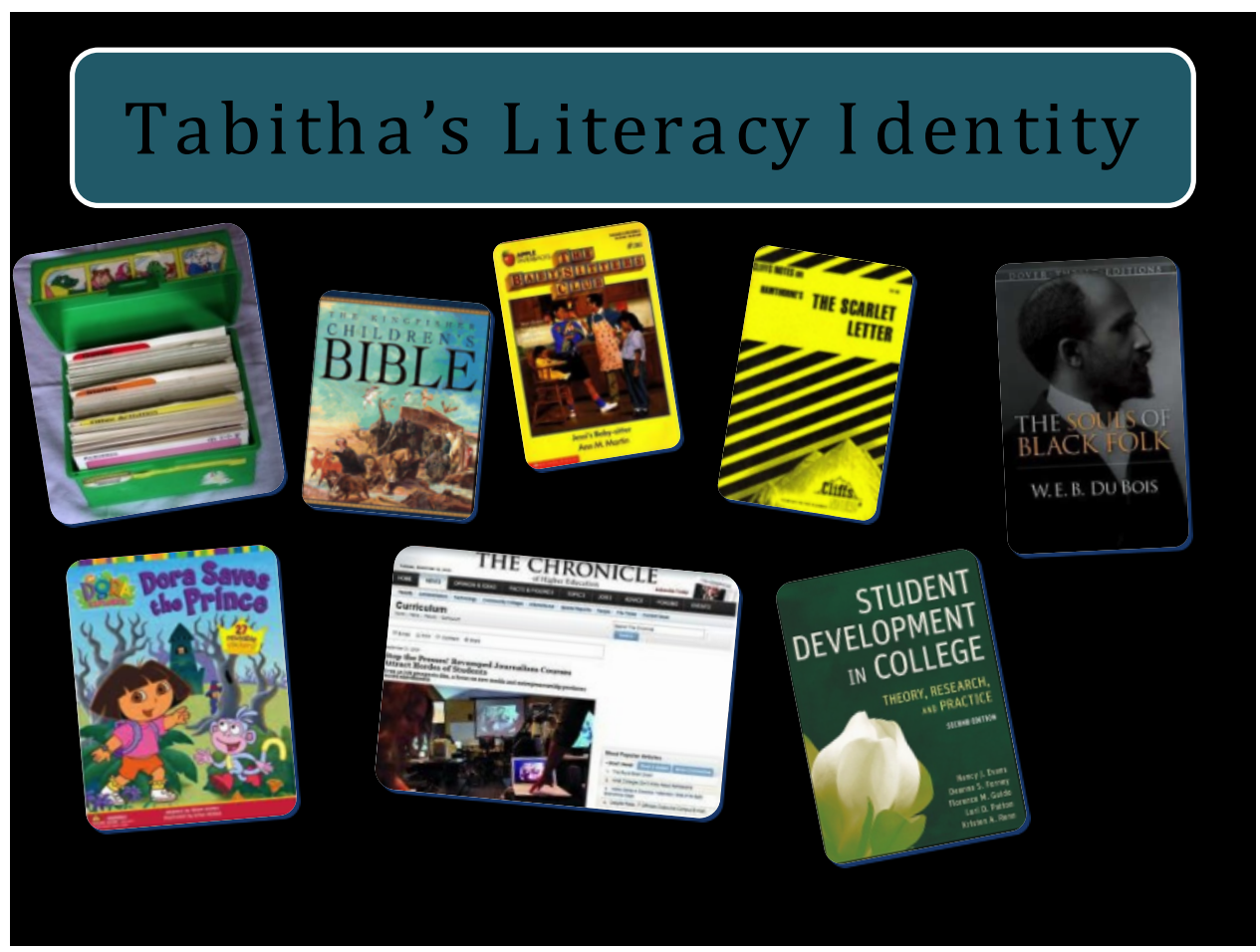

Figure 2. Tabitha's visual representation.

In describing her present literacy experiences, Tabitha shared that most of what she read was online and related to her studies. "I read for the purposes of getting information and I write for the purpose of communicating knowledge." With her peers in the doctoral program, she felt a sense of acceptance and belonging. "My reading and writing abilities in the past made me feel alienated, now I feel assimilated." Tabitha described herself a critical consumer of information and was proud of the fact that she can read and write with this type of perspective.

When asked what had impacted her literacy development in the doctoral program, Tabitha mentioned two specific support systems. The first support structure, created by her dissertation chair, met biweekly to work on their writing and was comprised of the chairs' advisees. The second group was called the DIVAS. This group of women came together to help each other prepare for comprehensive exams by reading and critiquing each other's writing.

In her interview, Tabitha did not describe many social experiences specifically related to literacy, however, she expressed tension that she often felt navigating between what she called her "two circles" which were comprised of her family/community and her academic colleagues. "I can speak and read and understand and deal with topics the same way that my peers do and so that makes me legitimate but in my community that makes me different because I speak differently. I speak the way I read and I speak the way I write." Tabitha added, "It makes me an elitist at home and kind of shapes the different ways I have to play around in my community." For Tabitha, her present literacy identity impacted her social experiences regardless of which "circle" she was in at a particular moment. This case illustrated the three indicators of academic success as previously discussed: 1) Retention: Tabitha is still enrolled in the doctoral program; 2) 
Academic Achievement: She described herself as a critical consumer and producer of information. In addition, Tabitha has successfully completed her coursework, exam requirements and is currently working on her dissertation; 3) Professional socialization: Participation in the writing group and biweekly discussions with her committee.

\section{Mixed Methods Findings}

The quantitative and qualitative data revealed participants' perceptions of their literacy identity and the impact of their past experiences on their present experiences as doctoral students. While they shared common themes, their individual experiences varied. In both case studies, participants discussed the role of family in their early literacy identity development. Catherine discussed shared reading experiences with her father and unlimited access to texts as meaningful and positive. On the survey, Catherine selected 5, the highest rating on the Likert scale, on reading and writing being encouraged and modeled in her home, whereas Tabitha selected 2 and 3 respectively. Although Tabitha expressed having access to reading materials, reading was not necessarily encouraged nor was it seen as a shared experience in her home and community. In response to question 1, "I have always enjoyed reading," and 2, "I have always enjoyed writing," Catherine rated both as a 5, Strongly Agree, while Tabitha rated these same items as a 1, Strongly Disagree. This is also evident in Catherine's desire to seek out reading and writing social groups, and Tabitha's disengagement with reading during middle and high school. Despite expressing different levels of enjoyment with reading and writing, the two participants self identified as successful readers and writers in the survey and interview data. In response to question five, "Growing up, I was a successful reader and writer," Catherine rated her experience as a 5 and Tabitha a 4 . They both shared stories of successful schooling experiences.

Despite varied literacy histories, both participants rated their previous reading and writing experiences as useful to their doctoral work and felt that they were successful in the program in part because of these experiences. In relation to these items they both agreed (4) or strongly agreed (5). Catherine and Tabitha also felt that previous experiences impacted their future career. Both participants expressed challenges in adjusting to the academic expectations of the doctorate program, such as reading scholarly research and writing in their discipline. However, they were able to overcome these challenges and contribute to their field as critical scholars. Both participants discussed positive experiences and increased confidence in their abilities as readers and writers in the Ph.D. program. They also shared specific stories of academic experiences that shifted their perceptions of their literacy identities in the doctoral program. For example, Tabitha revealed that her doctoral program made her feel legitimate because she "can speak, and read, and understand, and deal with topics the same way that [her] peers do."

The meaning participants attached to their literacy experiences were co-constructed in social settings (Vygotsky, 1978). All participants shared stories that illustrated social learning and literacy experiences. Catherine specifically talks about literacy as cultural capital, whereas Tabitha at times saw literacy as a limiting factor in social situations. During their doctoral program, participants noted additional literacy experiences which allowed them to communicate and collaborate with others including writing groups, and critical friends.

Participants described a range of support systems throughout their literacy development in the doctoral program; citing support from peers and university professors. These systems helped to shape participant identity and progress in numerous ways including providing critical feedback, creating learning communities and building confidence affirming the participants' 
persistence in the PhD program. These results are consistent with Gardner's (2009a) findings regarding the importance of support systems for doctoral students' persistence and success. Peer support was found to be a critical part of support systems for doctoral students.

\section{Discussion}

This study found that many graduate students begin their program with a successful literacy identity. The results of the survey indicate that most participants perceived themselves to be successful readers and writers in their past and felt that their past literacy experiences contributed in part to their success in the program. On average, the surveyed doctoral students rated question nine, "I am a successful doctoral student in part because of my previous experiences with literacy" as 4.14 on a scale of 1 to 5 indicating that previous literacy experiences contribute to success in higher education programs. Both Catherine and Tabitha discussed having a difficult transition into the doctoral program due to increased demands for reading and writing. Reading empirical research and theoretical works was new to Tabitha and Catherine as well as other new graduate students (Wao et al., 2009). Catherine explained that her literacy identity "took a hit" when she started the program. Both participants needed time to adjust to the rigorous demands of graduate work by learning to read and write in new ways for different purposes and audiences. Tabitha discussed having a sense of pride in the idea that she was able to generate new knowledge in her field. In addition, both participants expressed the importance of support systems in the doctoral program in the form of peers and feedback from professors. These support systems helped the participants feel more confident in their success as doctoral students.

We acknowledge that our findings are based on participant and researcher perceptions linking past literacy identity to current literacy experiences. While there is no statistical causal evidence, our qualitative findings suggest that past literacy experiences contribute to doctoral success as we define it: retention, academic achievement and professional socialization in doctoral programs. Knowledge and understanding of factors contributing to doctoral students' past, present and future literacy identities may help academic institutions better meet the graduate students' needs, improve the quality of their academic experiences, and reduce graduate program attrition rates. Researchers discuss the importance of students having feelings of success while engaged in the more challenging tasks of graduate education (Lavelle \& Bushrow, 2007; Shaw, 1999). It is also important for higher education to foster students' literacy identities as contributors to scholarship (Mullen, 1999; Wadsworth, Halfman, \& Upton, 2002) and professional fields (Faigley, 1981). As student identities and needs are examined and supported in doctoral programs, students may be better prepared to meet the demands of higher education and become better prepared for their future careers.

\section{Implications and Future Research}

This research highlights the impact of past and present literacy experiences on perceived student literacy identities and addresses a gap in the literature on literacy identity by emphasizing graduate students' need for continued support of academic experiences throughout their graduate career. In addition this study contributes to previous research by linking the literature on literacy identity and doctoral students. The study helped draw out the additional themes of social experiences and support systems which could impact attrition rates. The fields of teacher 
education and higher education will benefit from these findings in several ways. First, teacher education and higher education programs may profit from understanding doctoral students' selfperceptions and current literacy practices. The survey instrument and visual representation could be used as tools for university faculty to gain a better understanding of students' literacy identities and experiences. Utilizing results may allow staff to provide scaffolding for student learning. Second, these tools could be used by students as self-assessments for examining their literacy identities and the trajectory of their literacy development. This information could be used by students to determine the level of support from faculty and university support services. Third, students may benefit from a strong support system comprised of peers and/or faculty members who scaffold their academic literacy acquisition. Programs could foster the development of these support systems through writing groups, cohorts and mentors. If doctoral students feel supported and successful, attrition rates may be positively impacted. In addition, if faculties have a sense of doctoral students' literacy identities they may be better able to support them in their studies. Additional research could further explore the impact of doctoral students' literacy identities in their program and beyond. Future research could also examine social experiences and support systems in relation to doctoral students' persistence in higher education.

\section{Conclusion}

Limitations of this study include: a small number of participants, data collection within one doctoral program, and lack of data on student attrition. Nevertheless, this study addresses a gap in the literature that focuses on the combined fields of literacy and identity by linking them to success in higher education, underscoring the need for educational institutions to examine doctoral students' literacy experiences. Studies exploring literacy identities in other education programs as well as other disciplines should be conducted to more fully understand the role of literacy identity and support systems in graduate programs. In addition, this study could be replicated at the master's level.

While early literacy experiences were found to be important, based on the differences between Tabitha and Catherine, it is clear that early home literacy experiences do not necessarily dictate future success. Previous and present experiences that supported participants in higher education were found to be critical and consistent across the two case studies. This study shows the impact of support systems and how these systems continue to shape doctoral students' literacy identities. As students are supported in their doctoral programs they become better equipped and more confident in their abilities to be a critical consumer of scholarship and create new knowledge that contributes to their field. Furthermore, they are better positioned to enter the academe.

\section{References}

Bryman, A. (2006). Integrating quantitative and qualitative research: How is it done? Qualitative Research, 6(1), 97-113. doi: 10.1177/1468794106058877

Bustle, L. (2004). The role of visual representation in the assessment of learning, Journal of Adolescent and Adult Literacy, 47(5), 416-423.

Creswell, J. W. (2003). Research design: Qualitative, quantitative, and mixed methods approaches. Thousand Oaks, CA: Sage. 
Creswell, J. W., \& Plano Clark, V. L. (2011). Designing and conducting mixed methods research (2nd ed.). Thousand Oaks, CA: Sage.

Drake, C., Spillane, J. P., \& Hufferd-Ackles, K. (2001). Storied identities: Teacher learning and subject matter context. Journal of Curriculum Studies, 33(1), 1-23. doi: $10.1080 / 00220270119765$

Faigley, L. (1981). Writing after college: A stratified survey of the writing of college-trained people. Technical Report Number 1. Prepared through the Writing Program Assessment Project, University of Texas at Austin. (ERIC Document Reproduction Service No. ED210708).

Gardner, S. K. (2009a). Student and faculty attributions of attrition in high and low-completing doctoral programs in the United States. Higher Education: The International Journal of Higher Education And Educational Planning, 58(1), 97-112.

Gardner, S. K. (2009b). Conceptualizing success in doctoral education: Perspectives of faculty in seven disciplines. The Review of Higher Education, 32(3), 383-406.

http://dx.doi.org/10.1353/rhe.0.0075

Gee, J. P. (2006). Self-fashioning and shape-shifting: Language, identity, and social class. In D.E. Alvermann, K.A. Hinchman, D.W. Moore, S. F. Phelps, \& D.W. Raff (Eds.). Reconceptualizing the literacies in adolescents' lives (pp. 165-185). Mahwah, NJ: Erlbaum.

Greene, J. C., Caracelli, V. J., \& Graham, W. F. (1989). Toward a conceptual framework for mixed-method evaluation design. Educational Evaluation and Policy Analysis, 11, 255-274.

Guthrie, J. T., \& Alvermann, D. E. (1999) Engaged reading. New York: Teachers College.

Hayik, R. (2012). Identity representations in visual text. International Journal of Research \& Method in Education, 35(3), 293-309. doi: 10.1080/1743727X.2012.717435

Hall, L. A., \& Burns, L. D. (2009). Identity development and mentoring in doctoral education. Harvard Educational Review, 79(1), 49-70.

Holland, D., Lachicotte, W., Skinner, D., \& Cain, C. (1998). Identity and agency in cultural worlds. Cambridge, MA: Harvard University Press.

Ivankova, N., \& Stick, S. (2007). Students' persistence in a distributed doctoral program in educational leadership in higher education: A mixed methods study. Research in Higher Education, 48(1), 93-135. doi: 10.1007/s11162-006-9025-4

Ivankova, N. V., Creswell, J. W., \& Stick, S. L. (2006). Using mixed-methods sequential explanatory design: From theory to practice. Field Methods, 18(1), p. 3-20. doi: $10.1177 / 1525822$ X05282260 
Johnson, R. B., Onwuegbuzie, A. J., \& Turner, L. A. (2007). Toward a definition of mixed methods research. Journal of Mixed Methods Research, 1(2), 112-133. doi:

$10.1080 / 01443410701366001$

Lavelle, E., \& Bushrow, K. (2007). Writing approaches of graduate students. Educational Psychology, 27, 807-822.

Lave, J., \& Wenger, E. (1991). Situated learning: Legitimate peripheral participation.

Cambridge, UK: Cambridge University Press. doi: 10.1017/CBO9780511815355

Lincoln, Y. S., \& Guba, E. G. (1985). Naturalistic inquiry. Newbury Park, CA: Sage.

McAdams, D. P. (1993). The stories we live by: Personal myths and the making of the self. New York, NY: Morrow.

McCarthey, S. J. (2001). Identity construction in elementary readers and writers, Reading Research Quarterly, 36(2), 122-151. doi: 10.1598/RRQ.36.2.2

McCarthey, S. J. (1998). Constructing multiple subjectivities in classroom literacy contexts. Research in the Teaching of English, 32, 126-160.

Miles, M. B. \& Huberman, A. M. (1994). Qualitative data analysis, 2nd edition. Thousand Oaks, CA: Sage.

Moje, E. B., \& Luke, A. (2009). Literacy and identity: Examining the metaphors in history and contemporary research. Reading Research Quarterly, 44(4), 415-437.

http://dx.doi.org/10.1598/RRQ.44.4.7

Mullen, C. A. (2001). The need for a curricular writing model for graduate students. Journal of Further \& Higher Education, 25(1), 117-126. doi: 10.1080/03098770020030551

Mullen, C. A. (1999). "What I needed to know to get published": Teaching (frightened) graduate students to write for publication. Journal on Excellence in College Teaching, 10, 27-52.

Onwuegbuzie, A. J. (1997). Writing a research proposal: The role of library anxiety, statistics anxiety, and composition anxiety. Library and Information Science Research, 19, 5-33. http://dx.doi.org/10.1016/S0740-8188(97)90003-7

Schensul, S. L., Schensul , J. J. , \& LeCompte, M. D. (1999). Semi structured interviewing. In S.L. Schensul, J.J. Schensul, \& M.D. LeCompte, Essential ethnographic methods:

Observations, interviews and questionnaires (pp. 149- 164). Walnut Creek, CA: Altamira Press, a subsidiary of Sage Publications.

Shaw, V. N. (1999). Reading, presentation, and writing skills in content courses. College Teaching, 47, 153-57. doi: 10.1080/87567559909595808 
Shepard, R. (1993). Elementary media education: The perfect curriculum. English Quarterly, 25, 35-38.

Skerrett, A. (2012). "We hatched in this class:" Repositioning of identity in and beyond a reading classroom. The High School Journal, 95(3), 62-75. doi: 10.1353/hsj.2012.0008

Strauss, A., \& Corbin, J. (1998). Basics of qualitative research: Techniques and procedures for developing grounded theory (2nd ed.). Thousand Oaks, CA: Sage.

Vygotsky, L. S. (1978). Mind in society: The development of higher psychological processes. Cambridge, MA: Harvard University Press.

Wadsworth, J., Halfman, A. H., \& Upton, T. (2002). Strategies to improve the writing of graduate students. Rehabilitation Education, 16, 295-305.

Wao, H. O., Singh, O., Rich, V., Hohlfeld, T. N., Buckmaster, M., Passmore, D., Tonry, C., Onwuegbuzie, A. J., \& Jiao, Q. G. (2009). The perceived barriers toward reading empirical articles among graduate students: A mixed methods investigation. Journal of the Scholarship of Teaching and Learning, 9(3), p. $70-86$.

Williams, B. T. (2003). Heroes, rebels, and victims; Student identities in literacy narrative. Journal of Adolescent \& Adult Literacy, 47(4), 342-345.

Yin, R. K. (2009). Case study research design and methods. Thousand Oaks, CA. Sage Publications. 